\title{
Prior host-country work experience and immigrant labor market outcomes: evidence from Canada
}

\author{
Manish Pandey ${ }^{*}$ and James Townsend
}

\author{
${ }^{*}$ Correspondence: \\ m.pandey@uwinnipeg.ca \\ Department of Economics, \\ University of Winnipeg, 515 Portage \\ Avenue, Winnipeg, MB, R3B2E9, \\ Canada
}

\begin{abstract}
Recent changes to immigration selection policies favor skilled workers with prior work experience in the immigrant host country. Using unique administrative tax data for Canada, we estimate earnings equations to quantify the difference in earnings of immigrants with prior Canadian experience (prefilers) and those without prior experience (non-prefilers). We find that, relative to non-prefilers, entry earnings are higher for prefilers and, for male immigrants, this earnings advantage persists for at least 20 years after arrival. We show that the primary source of the higher entry earnings of prefilers is a higher return to foreign experience. In addition, the prefiler earnings advantage is largest for university graduates and the return to foreign experience is higher for prefilers from Western countries than those from the rest of the world. Our findings suggest that a move towards an immigrant selection system which uses previous host-country work experience as a criterion will improve the labor market performance of immigrants.
\end{abstract}

JEL Classification: J61, J31

Keywords: Immigrant selection, Earnings, Foreign experience returns, Canada

\section{Introduction}

For selecting skilled immigrants, countries design policies aimed at identifying individuals with the ability to succeed in the host country's labor market. ${ }^{1}$ In particular, countries use an employer-driven system, a migrant-driven system, or a combination of the two systems (Facchini and Lodigiani 2014). The primary difference between the two systems is that the former requires the applicant for immigration be employed or have a job offer in the host country but the latter typically does not. While most countries have some form of an employer-driven system, Australia, Canada, and New Zealand have relied primarily on migrant-driven systems and have developed criteria for selecting immigrants based on characteristics related to the human capital of potential immigrants, such as age, education, language ability, and work experience (Bertoli et al. 2016). ${ }^{2,3}$ For countries with migrant-driven systems, a number of recent studies have compared the labor market outcomes of immigrants admitted via programs using different selection criteria. ${ }^{4}$

Recent changes in immigration policies in countries with migrant-driven systems indicate a preference for skilled workers with prior experience in the immigrant host country. ${ }^{5}$

(c) The Author(s), 2017 Open Access This article is distributed under the terms of the Creative Commons Attribution 4.0 International License (http://creativecommons.org/licenses/by/4.0/), which permits unrestricted use, distribution, and reproduction in any medium, provided you give appropriate credit to the original author(s) and the source, provide a link to the Creative Commons license, and indicate if changes were made. 
In Canada, this preference is explicit in the eligibility criteria for the recently introduced Canadian Experience Class (CEC) program. ${ }^{6}$ The CEC represents a move away from the traditional migrant-driven system in which policy-makers used human capital characteristics to predict which candidates will be successful in the Canadian labor market. ${ }^{7}$ Previous employment in Canada implies that immigrants were preselected by Canadian employers and programs like the CEC use this preselection as an additional predictor of immigrant success. This direction in policy concedes a greater, albeit indirect, role to employers in selecting immigrants best suited for the Canadian labor market. The resulting program is a hybrid, combining elements of an employer-driven system (i.e., preselection) with those of a migrant-driven system. In this paper, we use a unique Canadian administrative dataset to compare the outcomes of immigrants with and without prior experience in Canada and evaluate whether changes in immigration policies that emphasize prior Canadian experience are likely to improve the selection of immigrants to Canada. Our findings will provide insights into whether a move towards a hybrid migrant-driven system, which bases selection on a combination of employer preselection and worker human capital characteristics, will improve the labor market performance of immigrants.

The Longitudinal Immigration Database (IMDB) provides data from the tax returns of all immigrants admitted to Canada since $1980 .{ }^{8}$ Given that the changes in Canadian immigration policies that prioritize immigrants with prior experience in the country are recent, the data available on the labor market performance of immigrants selected through these programs is not adequate for analysis. ${ }^{9}$ However, income tax returns filed by immigrants prior to obtaining permanent residence in Canada were recently added to the IMDB. We use this new data to distinguish between immigrants with prior Canadian experience (prefilers) and immigrants without prior experience (non-prefilers). Members of the former group had experience with the Canadian labor market prior to making the decision to immigrate. We use prefiling status as a proxy for this preselection of immigrants by employers and analyze the differences in earnings of the two groups of immigrants to determine whether prior experience in Canada is a predictor of labor market success of immigrants. Given that our focus is on the selection of immigrants, we limit our analysis to immigrants who are selected by Citizenship and Immigration Canada: principal applicants admitted through one of the economic immigration categories. ${ }^{10}$

We document the incidence of Canadian experience prior to immigration and find that $17 \%$ of male immigrants and $23 \%$ of female immigrants were prefilers. ${ }^{11}$ Given that most prefiling happens immediately prior to obtaining permanent resident status and consists of spells of 6 or fewer years, we restrict our analysis to immigrants that arrived in Canada between 1988 and 2009. ${ }^{12}$ This allows us to ensure comparability of the time of arrival for prefilers and non-prefilers. ${ }^{13}$

Previous studies of the performance of Canadian immigrants generally define the arrival year as the year in which an immigrant obtained permanent residence status in Canada (see, for example, Aydemir and Skuterud 2005; Green and Worswick 2012). Given that prefilers arrive in Canada before they obtain permanent residence, measures that treat the year of permanent residence as the arrival year will overstate foreign experience and understate Canadian experience. For a better measure of Canadian and foreign experience of immigrants, we organize the data around the year of arrival. Further, we follow Aydemir 
and Skuterud (2005) and restrict our analysis to immigrants aged 25 to 54 at the time of arrival. This age restriction implies that most immigrants will have completed their education prior to arriving in Canada.

We begin our analysis by comparing the earnings and characteristics of prefilers and non-prefilers. We find that both male and female prefilers tend to be on average 2 years younger than non-prefilers. However, while educational attainment is similar for male prefilers and non-prefilers, female prefilers have lower educational attainment. Further, prefilers are more likely than non-prefilers to be from Europe or the USA and to speak an official language of Canada as either the mother tongue or as a language learned prior to obtaining permanent resident status. For both male and female immigrants, prefilers have significantly higher mean earnings than non-prefilers 1 year after arrival.

We estimate a series of earnings models to characterize the earnings difference between prefilers and non-prefilers. To determine the magnitude of the difference, we estimate earnings equations by sex, excluding individual characteristics of immigrants. For males, we find that, relative to non-prefilers, entry earnings of prefilers are $72 \%$ higher. Furthermore, even though prefilers have a flatter earnings profile, earnings of the two groups of immigrants do not converge 20 years after arrival. Female prefilers have a smaller entry earnings advantage, and the earnings of female prefilers and non-prefilers converge in about 5 years.

We expand the regression model and include immigrant characteristics to determine whether observable differences between prefilers and non-prefilers can account for the difference in earnings. We find that differences in characteristics explain about a third of the entry earnings advantage of prefilers for males and about a quarter for females. Language and source region of immigrants account for most of this explained difference.

Aydemir and Skuterud (2005) and Green and Worswick (2010) find that recent cohorts of Canadian receive a negligible (or slightly negative) return to foreign experience. ${ }^{14}$ Given these findings, we expand our model to allow for differences in the returns to Canadian and foreign experience of prefilers and non-prefilers. We find that for both male and female immigrants, the primary source of the higher entry earnings of prefilers is a higher return to foreign experience in the Canadian labor market. While non-prefilers receive a negligible or small negative return to foreign experience, prefilers receive a positive return. In addition, the earnings dispersion by level of education is higher for prefilers, which suggests that prefilers receive a higher return to education than non-prefilers. We also estimate a specification that allows the return to differ across broad groupings of source regions and find that for both male and female immigrants, the return to foreign experience for prefilers from Western countries is higher than that for prefilers from other countries. $^{15}$

Our findings suggest that changes in immigration policies that increase the number of immigrants with prior Canadian experience will improve the average performance of immigrants in the Canadian labor market. In particular, given that the declining return to foreign experience has been highlighted as an important explanation for the decline in earnings of more recent cohorts of immigrants to Canada, our finding of a positive return to foreign experience for prefilers suggests that a policy shift towards retaining more workers on temporary work visas will result in better labor market outcomes for Canadian immigrants. ${ }^{16}$ This shift in policy will require that, in addition to allowing 
employers to address short-term labor shortages, temporary visa programs be recognized for their potential in identifying applicants for immigration with the ability to successfully integrate into the host country's labor market.

For policy-makers in countries developing criteria for selecting skilled immigrants (for example, the USA and Europe), our findings support introducing measures to retain temporary migrants who have been preselected by employers and to integrate temporary worker visa programs with the immigration selection process. ${ }^{17}$ The recent comprehensive immigration reforms proposed in the USA include selection criteria for skilled immigrants that reward prior experience in the USA (Boyd 2014). ${ }^{18}$ Our findings suggest that these reforms will result in selection of skilled immigrants that will perform well in the US labor market.

Our paper is related to two recent studies. Sweetman and Warman (2014) use data from the Longitudinal Survey of Immigrants to Canada (LSIC) to estimate the differences in earnings between immigrants that were temporary foreign workers and international students before immigrating to Canada. The LSIC data has a number of limitations. It has a small sample size and only includes applicants that applied for immigration from outside Canada and, hence, severely under-represents immigrants with prior Canadian experience. Hou and Bonikowska (2015) use IMDB data to examine the differences in earnings between immigrants with prior Canadian experience and those without. While estimates of the earnings advantage for prefilers in their study are similar to those that we find, they focus on quantifying the differences in earnings across visa categories (i.e., temporary foreign workers and international students) but do not examine how differences in characteristics and returns to human capital account for the difference in earnings between prefilers and non-prefilers. ${ }^{19}$

The rest of the paper is organized as follows. In Section 2, we provide a brief description of the data and present some summary statistics. In Section 3, we discuss the earnings equation that we estimate and present our findings. Section 4 provides a brief conclusion.

\section{Data}

The data is from the Longitudinal Immigration Database (IMDB), an administrative database that combines the immigration records and tax records of all immigrants to Canada that obtained permanent residence between 1980 and 2011 and also filed taxes at least once in a tax year between 1982 and $2012 .{ }^{20}$ We restrict our analysis to economic immigrants who were principal applicants, as the selection criteria apply to only these individuals. ${ }^{21}$ The arrival year for prefilers is the first year in which they filed taxes, while for non-prefilers, it is the year in which they obtained permanent residence. We further restrict our sample to individuals that were between the ages of 25 and 54 years at the time of arrival in Canada. The age restrictions imply that for the majority of individuals in our sample, human capital investments from postsecondary education were completed prior to arriving in Canada. Together, these restrictions imply that the majority of our prefilers were in Canada on work visas. ${ }^{22}$

The dependent variable in the regression is the natural logarithm of employment earnings, measured in 2002 dollars. ${ }^{23}$ To be included in the analysis, individuals were also required to have positive earnings in a given tax year. Since immigrants may have worked for only part of the year in which they arrived, we examine earnings starting with the first full year after arrival. To overcome the problem of an immigrant working part-time or for 
only part of a year to undertake further schooling, we exclude earnings for tax years in which an immigrant claims the full-time education tax credit.

For prefilers that filed taxes in Canada prior to 1982, these records are not included in the IMDB and as a result, the arrival year will be misattributed. This is likely to be a significant problem for immigrants arriving in the early years of the IMDB. We examine the pattern of tax filing of prefilers and find that for those that obtained permanent residence after 1992, less than $3 \%$ filed taxes in Canada 6 or more years prior to immigrating to Canada. Based on this finding, we minimize the misattribution of the arrival year for prefilers by including only those immigrants that arrived in Canada from 1988 onwards. A similar issue occurs in the later years of our sample; future immigrants that filed taxes between 1988 and 2011 but did not obtain permanent residence until 2012 or later will not be included in our sample. In addition, some immigrants obtaining permanent residence prior to 2012 will not have filed taxes yet and will not be in the IMDB. To address these issues, we further restrict our analysis to immigrants that arrived in Canada no later than $2009 .{ }^{24}$

Given that the data is not a balanced panel, we use the characteristics of immigrants filing taxes in the first year after arrival to establish the mean characteristics of prefilers and non-prefilers. Immigrant characteristics in the IMDB, such as education and language ability, are recorded at the time of obtaining permanent residence in Canada and do not change over time. Table 1 provides summary statistics for a variety of characteristics by sex and prefiling status. ${ }^{25}$ Of the immigrants that we consider, $17.3 \%$ of male immigrants were prefilers, while $23 \%$ of female immigrants filed taxes prior to obtaining permanent residence in Canada. For prefilers, the frequency with which taxes are filed prior to obtaining permanent residence is similar for both sexes; roughly a third file taxes once, another half file two or three times, and less than $2 \%$ file more than six times.

A comparison of the mean characteristics of male prefilers and non-prefilers reveals several differences. Male prefilers tend to be on average 2 years younger than nonprefilers, which, given similar levels of educational attainment, implies that they have lower average levels of foreign experience at arrival. ${ }^{26}$ While female prefilers are on average 2 years younger than non-prefilers, their level of educational attainment is lower. However, the combined effect of age and education level implies lower levels of foreign experience for female prefilers as well.

There are marked differences between the source regions and language characteristics of the two groups. In particular, male prefilers are much more likely to come from Europe and the USA but less likely to come from Asia. This is reflected in the language variablesprefilers are more likely to have English as a mother tongue, and even when English is not the mother tongue, prefilers are more likely to indicate knowledge of English. In contrast, with the exception of those whose mother tongue is French and also know English, prefilers are less likely to speak French. Further, there are differences in the source region patterns between males and females. Relative to non-prefilers, female prefilers are less likely to come from Europe but are equally likely to come from Asia. However, as was the case for males, the language abilities of female prefilers are better than those of non-prefilers.

The two groups differ in their province of residence. While $54 \%$ of male non-prefilers live in Canada's largest province, Ontario, only $43 \%$ of prefilers reside in the province. In contrast, prefilers are more likely to live in Alberta, Manitoba, Saskatchewan, and 
Table 1 Summary statistics by gender and prefiling status (1 year after arrival)

\begin{tabular}{|c|c|c|c|c|}
\hline \multirow[b]{2}{*}{ Prefiler } & \multicolumn{2}{|l|}{ Male } & \multicolumn{2}{|l|}{ Female } \\
\hline & No & Yes & No & Yes \\
\hline \multicolumn{5}{|c|}{ Age, marital status, and labor experience } \\
\hline Age at arrival (mean) & 35.5 & 33.3 & 34.3 & 32.1 \\
\hline Married ${ }^{\mathrm{a}}$ & 69.8 & 66.9 & 51.8 & 37.9 \\
\hline Foreign exper. (mean) & 14.1 & 12.0 & 12.7 & 11.8 \\
\hline \multicolumn{5}{|c|}{ Highest educational attainment ${ }^{a}$} \\
\hline H.S. or less & 18.9 & 21.9 & 18.9 & 32.0 \\
\hline Some P.S. & 13.8 & 12.1 & 15.4 & 16.2 \\
\hline University & 67.3 & 65.7 & 65.7 & 50.8 \\
\hline \multicolumn{5}{|l|}{ Region of origin ${ }^{a}$} \\
\hline Europe & 22.6 & 28.2 & 24.9 & 19.8 \\
\hline Africa & 9.9 & 10.9 & 8.5 & 5.8 \\
\hline Asia & 61.2 & 44.2 & 56.2 & 55.8 \\
\hline Americas & 5.6 & 9.4 & 9.2 & 12.6 \\
\hline USA & 0.5 & 5.8 & 0.9 & 4.1 \\
\hline Oceania & 0.2 & 1.3 & 0.3 & 1.4 \\
\hline \multicolumn{5}{|c|}{ Mother tongue/official language $\mathrm{a}^{\mathrm{a}}$} \\
\hline Engl./Engl. & 7.3 & 19.7 & 10.2 & 18.0 \\
\hline Engl./both & 0.3 & 1.2 & 0.7 & 1.1 \\
\hline Fren./Fren. & 1.7 & 1.1 & 2.0 & 0.9 \\
\hline Fren./both & 2.5 & 4.4 & 4.0 & 4.3 \\
\hline Neither/Engl. & 55.8 & 56.4 & 50.5 & 59.7 \\
\hline Neither/Fren. & 3.5 & 1.7 & 3.5 & 1.6 \\
\hline Neither/both & 10.8 & 7.1 & 14.7 & 7.0 \\
\hline Neither/neither & 18.2 & 7.1 & 14.2 & 5.0 \\
\hline \multicolumn{5}{|c|}{ Province of residence (tax-based) } \\
\hline Atlantic & 0.8 & 3.2 & 0.5 & 1.0 \\
\hline Quebec & 16.7 & 17.5 & 20.2 & 18.8 \\
\hline Ontario & 54.2 & 43.3 & 49.1 & 42.8 \\
\hline Manitoba & 2.9 & 4.9 & 3.1 & 3.2 \\
\hline Sask. & 0.7 & 3.6 & 0.7 & 1.8 \\
\hline Alberta & 7.6 & 12.1 & 6.7 & 10.6 \\
\hline B.C. & 17.0 & 14.4 & 19.3 & 19.2 \\
\hline \multicolumn{5}{|l|}{ Earnings } \\
\hline Empl. earnings (mean) & 24,300 & 47,100 & 18,600 & 23,800 \\
\hline \multicolumn{5}{|l|}{ Years of prefiling } \\
\hline Once & - & 35.7 & - & 31.7 \\
\hline $2-3$ & - & 47.5 & - & 55.2 \\
\hline $4-6$ & - & 14.8 & - & 12.2 \\
\hline $7+$ & - & 1.9 & - & 1.0 \\
\hline No. of obs. & 342,460 & 71,405 & 116,120 & 34,705 \\
\hline
\end{tabular}

Source: IMDB custom tabulations, see footnote 25 for details. Note: All figures are percentages unless otherwise indicated ${ }^{a}$ Recorded when permanent residence was obtained

the Atlantic provinces. Similar patterns hold for female immigrants. These patterns are likely explained in part by the Provincial Nominee Programs, which were intended to increase regional dispersion of economic immigrants and often provide a path to permanent residence for temporary foreign workers already residing in the nominating province. 
Mean earnings of male prefilers are nearly twice as high as those of non-prefilers in the year immediately following arrival. The patterns differ somewhat for female immigrantsaverage earnings of prefilers are roughly a third higher than those of non-prefilers. Figure 1 plots the trajectory of the difference in mean log employment earnings between prefilers and non-prefilers. To adjust for year-of-arrival effects, we first compute the mean difference between prefilers and non-prefilers that arrived in the same year with the same number of years since arrival. These differences are then averaged over all yearof-arrival cohorts with the same number of years since arrival. There is a sizeable initial mean log earnings advantage for prefilers of $0.58 \log$ points for males. Although the difference decreases with years since arrival, the advantage is still approximately $0.20 \log$ points 15 years after arrival. Qualitatively, the pattern is similar for females, though the initial advantage is smaller ( $0.20 \mathrm{log}$ points) and has vanished (or turned into a small disadvantage) 15 years after arrival. In the next section, we estimate regressions to further investigate the differences in earnings between prefilers and non-prefilers and the extent to which differences in characteristics (and their returns) can account for these differences.

\section{Earnings of prefilers versus non-prefilers}

Using the data described in the previous section, we begin by estimating an earnings equation to characterize differences between the earnings profiles of prefilers and non-prefilers. We then expand this model to quantify the ability of differences in characteristics and their returns to account for the differences in earnings between the two groups. We follow previous studies examining earnings of immigrants in Canada (for example, Aydemir and Skuterud 2005) and estimate the following earnings equation:

$$
\begin{aligned}
\ln \left(\operatorname{earn}_{i, j, t}\right)= & \beta_{0}+\beta_{1} \mathrm{ysa}_{i, t}+\beta_{2} \mathrm{ysa}_{i, t}^{2}+\gamma_{0} \text { prefil }_{i}+\gamma_{1} \text { prefil }_{i} \cdot \mathrm{ysa}_{i, t}+\gamma_{2} \operatorname{prefil}_{i} \cdot \mathrm{ysa}_{i, t}^{2} \\
& +\sum_{j=1}^{J}\left(\alpha_{0 j} \text { cohort }_{j}+\alpha_{1 j} \text { cohort }_{j} \cdot \mathrm{ysa}_{i, t}\right)+\theta X_{i, t}+\epsilon_{i, t}
\end{aligned}
$$

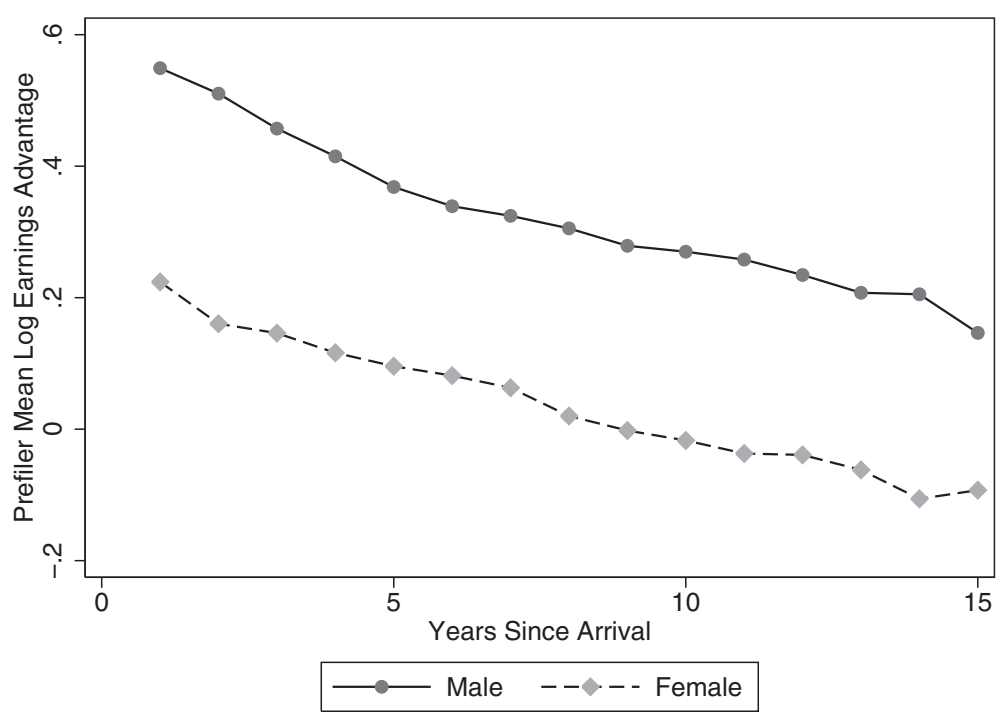

Fig. 1 Mean log earnings gap of prefilers by years since arrival 
The dependent variable, $\ln \left(\operatorname{earn}_{i, j, t}\right)$, is the logarithm of earnings of immigrant $i$ that arrived in Canada in period $j$ in tax year $t$. The earnings equation includes a quadratic term in years since arrival (ysa), which is allowed to vary between prefilers (prefil $=1$ ) and non-prefilers (prefil $=0$ ). Given the extensive evidence of differences in entry earnings for immigrants entering Canada in different time periods (see, for example, Aydemir and Skuterud 2005; Green and Worswick 2012), we also include arrival period cohort dummies (cohort) and the interaction of these dummies with ysa to allow both entry earnings and the shape of the earnings profile after arrival to differ across arrival cohorts. ${ }^{27} \mathrm{X}$ is a vector of individual characteristics of immigrants, which includes marital status, level of educational attainment, knowledge of official languages of Canada (defined as various interactions between mother tongue and indication of familiarity with one or both of Canada's official languages), and source region of the immigrant (the six broad regions outlined in Section 2). In addition, based on Mincer's method, we include an imputed measure of experience in which years of schooling for different levels are used to construct a measure of potential experience for an immigrant. ${ }^{28}$ We also include the unemployment rate in the province of residence and provincial dummy variables. ${ }^{29}$ To account for correlations across individuals arising from unobserved provincial economic conditions, in all regressions, we compute standard errors by clustering on province of residence.

We begin by estimating regression (1) by sex, without the individual characteristics and provincial variables, to obtain unconditional earnings profiles. Model 1 in Table 2 provides the resulting coefficient estimates. For both sexes, our results are consistent with the previous literature; the coefficient estimates for ysa and $\mathrm{ysa}^{2}$ indicate that earnings increase at a decreasing rate with years since arrival. ${ }^{30}$ For males, the estimates of prefil and its interaction with the slope term indicate that, relative to non-prefilers, prefilers have about $72 \%$ higher entry earnings and, even though they have a flatter earnings profile, the earnings of the two groups of immigrants do not converge 20 years after arrival. Female prefilers have a lower entry earnings advantage (24\%), and their earnings converge to those of non-prefilers in about 5 years. These findings are very similar to the patterns established in Fig. 1.

Next, we estimate regression (1) including individual and provincial variables. Model 2 in Table 2 provides the results. The estimates for the control variables for both males and females are consistent with those in previous studies (Aydemir and Skuterud 2005; Hou and Bonikowska 2015). Relative to university-educated immigrants, those with some postsecondary schooling (someps) or a high school degree or less of education (hsorless) have lower earnings; provincial unemployment is negatively related to immigrant earnings; immigrants with knowledge of English have higher earnings; and immigrants from Europe, the USA, and Oceania have higher earnings than immigrants from other source regions.

After controlling for observable differences, entry earnings of male prefilers are about $41 \%$ higher than those of non-prefilers. Comparing the estimates of the coefficient on prefil from the unconditional (model 1) and conditional (model 2) model suggests that observable differences can explain more than a third of the entry earnings advantage of male prefilers. Using the estimated coefficients from model 2 and the characteristics in Table 1, differences in individual characteristics account for $0.17 \log$ points of the earnings difference between prefilers and non-prefilers 1 year after arrival, most of which is due to differences in language (0.09) and source region (0.06). ${ }^{31}$ Differences in province 
Table 2 Earnings profile

\begin{tabular}{|c|c|c|c|c|c|c|c|c|}
\hline & \multicolumn{4}{|c|}{ Male } & \multicolumn{4}{|c|}{ Female } \\
\hline & \multicolumn{2}{|c|}{ Model 1} & \multicolumn{2}{|c|}{ Model 2} & \multicolumn{2}{|c|}{ Model 1} & \multicolumn{2}{|c|}{ Model 2} \\
\hline & Estimate & S.E. & Estimate & S.E. & Estimate & S.E. & Estimate & S.E. \\
\hline Prefil & $0.541^{* * *}$ & 0.079 & $0.342^{* * *}$ & 0.048 & $0.215^{*}$ & 0.090 & $0.155^{*}$ & 0.070 \\
\hline Prefil*ysa & $-0.041^{* * *}$ & 0.003 & $-0.041^{* * *}$ & 0.003 & $-0.042^{* * *}$ & 0.005 & $-0.044^{* * *}$ & 0.005 \\
\hline Prefil $^{*} y s a^{2}$ & $0.001^{* * *}$ & 0.000 & $0.001^{* * *}$ & 0.000 & $0.001^{* * *}$ & 0.000 & $0.001^{* * *}$ & 0.000 \\
\hline Ysa & $0.079 * * *$ & 0.007 & $0.086^{* * *}$ & 0.005 & $0.081^{* * *}$ & 0.002 & $0.084^{* * *}$ & 0.003 \\
\hline Ysa2 & $-0.002^{* * *}$ & 0.000 & $-0.002^{* * *}$ & 0.000 & $-0.002^{* * *}$ & 0.000 & $-0.002^{* * *}$ & 0.000 \\
\hline Ysa*9092 & $0.007^{* * *}$ & 0.001 & $0.004^{*}$ & 0.002 & $0.007^{* * *}$ & 0.001 & $0.006^{* * *}$ & 0.001 \\
\hline Ysa*9396 & $0.006^{*}$ & 0.002 & $0.007^{* * *}$ & 0.001 & $0.008^{* *}$ & 0.003 & $0.011^{* *}$ & 0.004 \\
\hline Ysa*9799 & -0.003 & 0.005 & $0.006^{* *}$ & 0.002 & 0.001 & 0.001 & $0.008^{* * *}$ & 0.002 \\
\hline Ysa*0003 & $0.020^{* * *}$ & 0.004 & $0.032^{* * *}$ & 0.001 & $0.024^{* * *}$ & 0.002 & $0.034^{* * *}$ & 0.004 \\
\hline Ysa*0407 & $0.029^{* * *}$ & 0.002 & $0.045^{* * *}$ & 0.005 & $0.038^{* * *}$ & 0.006 & $0.051^{* * *}$ & 0.007 \\
\hline Ysa*0809 & $0.084^{* * *}$ & 0.010 & $0.085^{* * *}$ & 0.014 & $0.093^{* * *}$ & 0.013 & $0.095^{* * *}$ & 0.016 \\
\hline Coh9092 & $-0.132^{* * *}$ & 0.015 & $-0.090^{* * *}$ & 0.022 & $-0.134^{* * *}$ & 0.028 & $-0.121^{* * *}$ & 0.029 \\
\hline Coh9396 & 0.025 & 0.048 & $-0.100^{* * *}$ & 0.016 & -0.064 & 0.056 & $-0.196^{* * *}$ & 0.052 \\
\hline Coh9799 & $0.192^{* * *}$ & 0.056 & -0.059 & 0.037 & $0.135^{*}$ & 0.054 & $-0.113^{*}$ & 0.047 \\
\hline Coh0003 & 0.050 & 0.046 & $-0.207^{* * *}$ & 0.057 & 0.050 & 0.060 & $-0.212^{* *}$ & 0.072 \\
\hline Coh0407 & 0.029 & 0.092 & $-0.202^{*}$ & 0.093 & -0.020 & 0.099 & $-0.283^{* *}$ & 0.104 \\
\hline Coh0809 & -0.133 & 0.098 & $-0.273^{*}$ & 0.106 & $-0.259^{*}$ & 0.123 & $-0.460^{* * *}$ & 0.119 \\
\hline Married & & & $0.151^{* * *}$ & 0.015 & & & -0.010 & 0.011 \\
\hline Nfld & & & $0.718^{* * *}$ & 0.062 & & & $0.288^{* * *}$ & 0.049 \\
\hline Pei & & & -0.000 & 0.040 & & & -0.025 & 0.039 \\
\hline Nscotia & & & -0.037 & 0.027 & & & $-0.253^{* * *}$ & 0.025 \\
\hline Nbrunswick & & & $0.215^{* * *}$ & 0.041 & & & -0.015 & 0.035 \\
\hline Quebec & & & $-0.127^{* * *}$ & 0.019 & & & $-0.208^{* * *}$ & 0.018 \\
\hline Manitoba & & & $0.055^{*}$ & 0.024 & & & $0.039^{* *}$ & 0.015 \\
\hline Sask & & & $0.147^{* * *}$ & 0.025 & & & $0.103^{* * *}$ & 0.021 \\
\hline Alberta & & & $0.269^{* * *}$ & 0.015 & & & $0.101^{* * *}$ & 0.011 \\
\hline$B C$ & & & 0.003 & 0.017 & & & $-0.061^{* * *}$ & 0.013 \\
\hline Unemp & & & $-0.037^{* * *}$ & 0.006 & & & $-0.023^{* * *}$ & 0.004 \\
\hline $\mathrm{Fr}^{*} \mathrm{fr}$ & & & $-0.336^{* * *}$ & 0.015 & & & $-0.161^{* * *}$ & 0.033 \\
\hline Eng*both & & & -0.049 & 0.040 & & & -0.028 & 0.043 \\
\hline Fr*both & & & $-0.179^{* * *}$ & 0.012 & & & -0.037 & 0.031 \\
\hline $\mathrm{Ne}^{*}$ eng & & & $-0.417^{* * *}$ & 0.031 & & & $-0.283^{* * *}$ & 0.044 \\
\hline $\mathrm{Ne}^{*} \mathrm{fr}$ & & & $-0.599^{* * *}$ & 0.006 & & & $-0.436^{* * *}$ & 0.046 \\
\hline $\mathrm{Ne}^{*}$ both & & & $-0.438^{* * *}$ & 0.029 & & & $-0.271^{* * *}$ & 0.018 \\
\hline $\mathrm{Ne}^{*}$ neither & & & $-0.623^{* * *}$ & 0.019 & & & $-0.554^{* * *}$ & 0.038 \\
\hline Africa & & & $-0.135^{* *}$ & 0.045 & & & -0.026 & 0.066 \\
\hline Asia & & & $-0.323^{* * *}$ & 0.026 & & & -0.104 & 0.054 \\
\hline Americas & & & $-0.120^{* * *}$ & 0.035 & & & $-0.093^{* * *}$ & 0.024 \\
\hline US & & & 0.154 & 0.098 & & & $0.288^{* * *}$ & 0.069 \\
\hline Oceania & & & 0.011 & 0.080 & & & $0.167^{* *}$ & 0.058 \\
\hline Exp & & & -0.010 & 0.007 & & & -0.003 & 0.004 \\
\hline Exp2 & & & $-0.000^{* *}$ & 0.000 & & & $-0.000^{* * *}$ & 0.000 \\
\hline Hsorless & & & $-0.275^{* * *}$ & 0.026 & & & $-0.353^{* * *}$ & 0.025 \\
\hline Someps & & & $-0.195^{* * *}$ & 0.021 & & & $-0.219^{* * *}$ & 0.009 \\
\hline Constant & $9.683^{* * *}$ & 0.086 & $10.981^{* * *}$ & 0.164 & $9.451^{* * *}$ & 0.116 & $10.415^{* * *}$ & 0.129 \\
\hline$N$ & $4,225,855$ & & $4,225,855$ & & $1,693,520$ & & $1,693,520$ & \\
\hline$R^{2}$ & 0.051 & & 0.150 & & 0.050 & & 0.117 & \\
\hline
\end{tabular}

Notes: The dependant variable is the log of real earnings. Standard errors are clustered by province of residence. The reference group consists of a single immigrant with a university degree, migrating from Europe in 1988-1989, whose mother tongue and official language is English, and who is originally destined for Ontario $*^{* * *}, * * *$ * Significant at $0.01,0.05$, and 0.10 levels, respectively 
of residence, provincial unemployment rates, and period of arrival account for an additional difference of $0.03 \log$ points. As was the case for model 1 , the negative coefficient estimate for prefil $*$ ysa in model 2 indicates that the earnings profile of prefilers is flatter than that of non-prefilers, implying that the conditional mean earnings of the two groups of immigrants converge in about 11 years. The estimates for females suggest a similar pattern. However, observable differences between female immigrants explain only about a quarter of the prefiler entry earnings advantage. ${ }^{32}$

Prefilers are preselected by employers prior to applying for and obtaining permanent residence in Canada. Our findings suggest that preselection is associated with earnings that are significantly higher than those of other immigrants at entry and that this earnings advantage persists for a number of years following arrival. The earnings advantage for preselected immigrants is only partially explained by observable characteristics. This suggests that preselection by employers is associated with characteristics that imply greater suitability of the immigrant to the Canadian labor market. Further, while these characteristics are observed by employers, the Canadian immigration selection system either does not use them or uses them differently. Hence, our findings provide indirect evidence that recent changes in immigration policies which incorporate employer preselection will improve the labor market performance of immigrants in Canada.

\subsection{Explaining higher entry earnings of prefilers}

In what follows, we estimate two extended versions of our model from the previous section. In the first extension, we distinguish between foreign and Canadian experience and allow the returns for both to differ between prefilers and non-prefilers. We hypothesize that prefilers, having worked in Canada prior to immigrating, are more likely to receive positive returns to their foreign experience. We also allow the returns to education to differ between the two groups to allow for the possibility of greater recognition of educational credentials. In the second extension, we expand the model to further distinguish between immigrants from Western and non-Western countries. Our previous findings regarding the importance of language ability and source country in explaining differences suggest that Western prefilers (and non-prefilers) may have different outcomes from their counterparts from non-Western countries.

\subsubsection{Returns to education and experience}

To explain the earnings advantage of prefilers, we allow for differences in returns to education levels, Canadian experience, and foreign experience between prefilers and non-prefilers. To regression (1), we add interaction terms of prefiler status with educational attainment, Canadian experience, and foreign experience (both linear and quadratic terms). ${ }^{33}$ In addition, to allow for differences in returns to experience across arrival cohorts, we include interactions between the arrival cohort dummies and each of Canadian and foreign experience.

The estimates for the variables of interest are presented in Table 3. The interaction between each of Canadian and foreign experience and the arrival cohort dummies indicates that, relative to the 1988-1989 cohort, the returns to Canadian experience have been higher and the returns to foreign experience have been lower for more recent arrival cohorts. 
Table 3 Canadian and foreign experience (model 3)

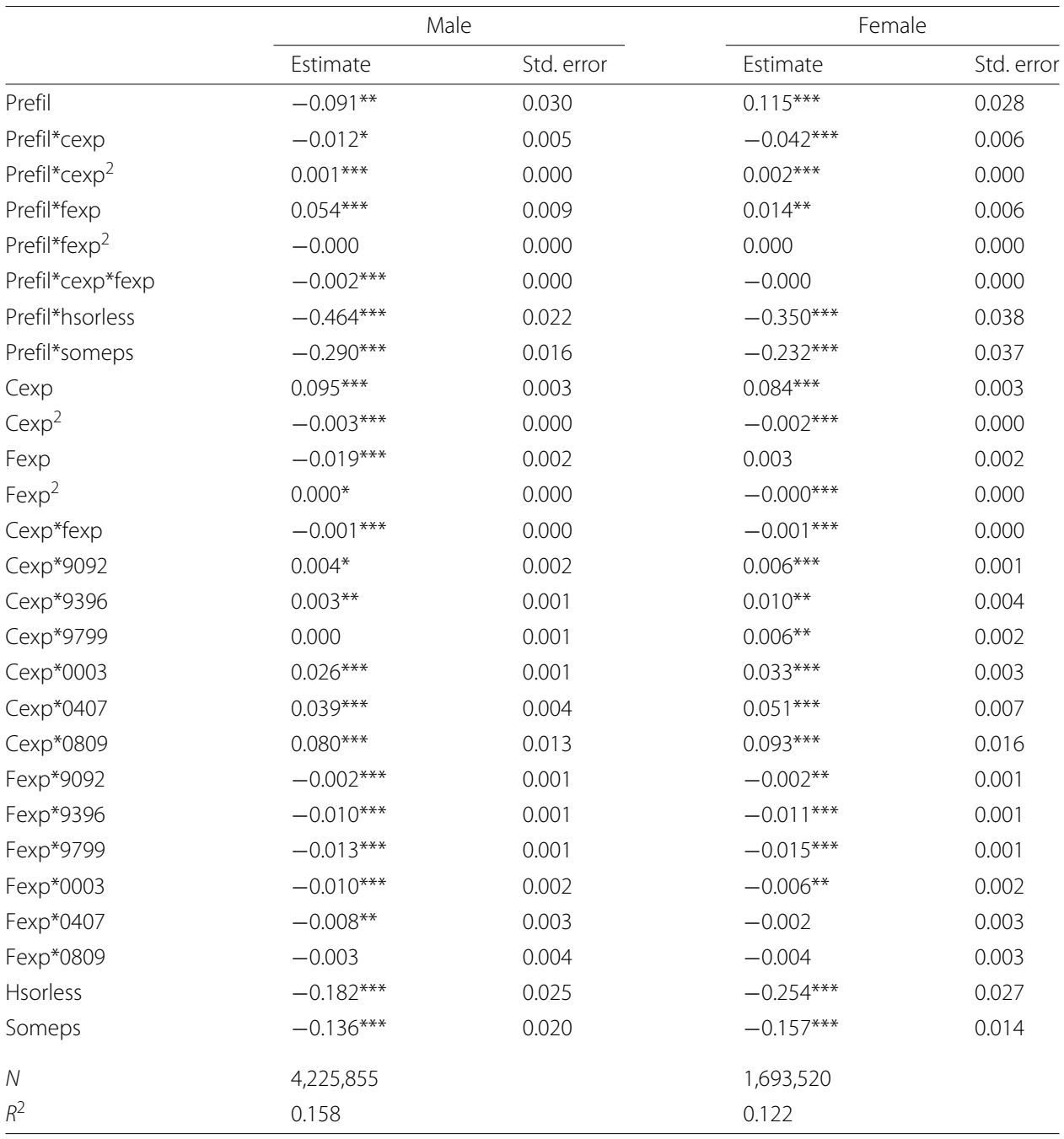

Notes: The dependant variable is the log of real earnings. The regression includes all the control variables in the conditional regression presented in Table 2. Standard errors are clustered by province of residence $* * * * * *$ Significant at $0.01,0.05$, and 0.10 levels, respectively

The estimates indicate that there are differences in the returns to foreign experience between prefilers and non-prefilers. While male non-prefilers receive a negative return to a year of foreign experience (the estimate is $-0.019 \log$ points for the 1988-1989 cohort, whereas the lowest return is $-0.032 \log$ points for the $1997-1999$ cohort), male prefilers receive a positive return $(0.035 \log$ points for the 1988-1989 cohort and $0.022 \mathrm{log}$ points for the 1997-1999 cohort). This suggests that a large part of the earnings advantage of male prefilers is due to higher valuation of their foreign experience by the Canadian labor market. Similar to male immigrants, female prefilers receive a higher return to their foreign experience than non-prefilers. However, the difference in the returns to foreign experience between female prefilers and non-prefilers is smaller in magnitude than that for male immigrants, which explains why the earnings advantage of female prefilers is not as high as that for male prefilers. ${ }^{34}$

The negative coefficient on the interaction term prefil $* \operatorname{cexp} *$ fexp for male immigrants indicates that the earnings-Canadian-experience profile will be flatter for prefilers 
arriving with more foreign experience. Together with the higher returns to foreign experience, this implies that compared to observationally equivalent non-prefilers, the initial earnings gap increases with foreign experience, but this gap will close more rapidly with the accumulation of Canadian experience. We illustrate this in Fig. 2, which plots the fitted earnings gap between university-educated male prefilers and non-prefilers with varying levels of foreign experience at the time of arrival. The gap increases with years of foreign experience, albeit at a decreasing rate, with an advantage evident for prefilers with as little as 5 years of foreign experience. Furthermore, the advantage for male prefilers persists throughout the first 20 years in Canada. In contrast, female prefilers (Fig. 3) have a smaller return to foreign experience. In addition, their earnings profiles after arrival are flatter than those of their non-prefiling counterparts, regardless of their level of foreign experience. Nevertheless, university-educated female prefilers with 10 or more years of foreign experience receive an earnings advantage that persists for 10 or more years after arrival.

Greater transferability of human capital for prefilers extends to education as well. For both male and female immigrants, the coefficients on the educational variables indicate that non-prefilers receive a lower return to their education than prefilers. For instance, holding all else constant, a university-educated male non-prefiler earns $20 \%$ more than a non-prefiler with a high school or less education and $15 \%$ more than a non-prefiler with some postsecondary education. For male prefilers, the figures are 91 and $53 \%$, respectively. Together, these findings indicate that the biggest advantage of preselection is experienced by university-educated immigrants. In particular, for male prefilers with less than a university degree, the higher return to foreign experience will not generally offset the lower entry earnings and the lower return to Canadian experience. To match entry earnings of an observationally equivalent non-prefiler, a prefiler with postsecondary education requires 7 years of foreign experience, while a prefiler with at most a high school diploma requires 10 years. Similar patterns hold for female immigrants. However, given the lower return to foreign experience, female prefilers with less than a

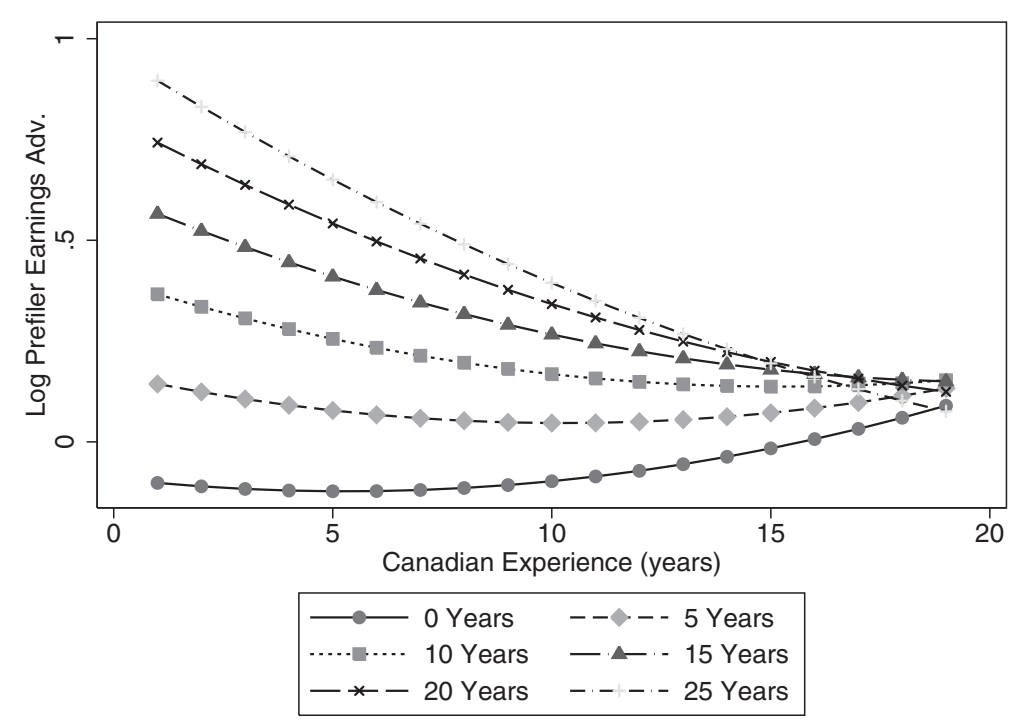

Fig. 2 Prefiler earnings advantage by years of foreign experience: male immigrants 


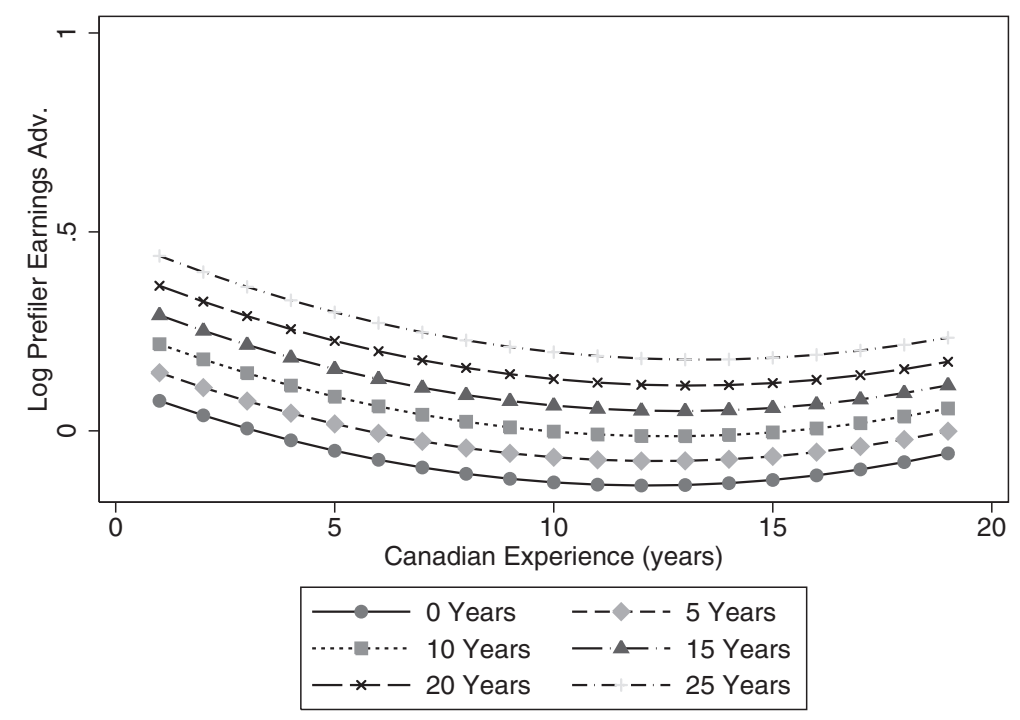

Fig. 3 Prefiler earnings advantage by years of foreign experience: female immigrants

university education will be at a permanent earnings disadvantage relative to equivalent non-prefilers.

Our findings suggest that differences in the return to foreign experience between prefilers and non-prefilers are the primary reason for the entry earnings advantage of prefilers. The higher returns to foreign experience for prefilers compared to non-prefilers may be due to better credential recognition for the former group of immigrants. Furthermore, given the greater earnings dispersion by educational level and the lower returns to Canadian experience for prefilers, relative to observationally equivalent non-prefilers, only university-educated prefilers with some foreign experience or less-educated prefilers with significant amounts of foreign experience will experience an earnings advantage for more than a few years following arrival. Therefore, our findings suggest that in selecting immigrants, placing more weight on foreign experience for university-educated male and female applicants that have worked in Canada previously and less weight on this factor for those without prior experience will improve the average performance of immigrants in the Canadian labor market.

\subsubsection{Source region differences}

Given the large role that source country plays in explaining earnings differences between prefilers and non-prefilers, we investigate how the returns to experience and educational attainment vary by source region for the two groups. To do so, we divide our sample into immigrants from Western countries (West) and those from the remaining countries (Rest). ${ }^{35}$ We expand model 3 to include indicators for each of prefil and West, which are fully interacted with each of foreign experience, Canadian experience, and educational attainment. The estimates of the variables of interest are presented in Table 4. The estimated coefficients for male immigrants on the interactions of West with the remaining variables suggest that, while non-prefiling immigrants from Western countries have similar returns to education as non-prefiling immigrants from the remaining 
Table 4 West versus Rest (model 4)

\begin{tabular}{|c|c|c|c|c|}
\hline & \multicolumn{2}{|c|}{ Male } & \multicolumn{2}{|c|}{ Female } \\
\hline & Estimate & Std. error & Estimate & Std. error \\
\hline Prefil & $-0.133^{* * *}$ & 0.039 & 0.016 & 0.041 \\
\hline Prefil* ${ }^{*} \exp$ & -0.004 & 0.006 & $-0.032^{* * *}$ & 0.007 \\
\hline Prefil $^{*} \operatorname{cexp}^{2}$ & $0.001^{* * *}$ & 0.000 & $0.001^{* * *}$ & 0.000 \\
\hline Prefil*fexp & $0.042^{* * *}$ & 0.012 & 0.009 & 0.007 \\
\hline Prefil*fexp ${ }^{2}$ & -0.000 & 0.000 & 0.000 & 0.000 \\
\hline Prefil $^{*} c \exp { }^{*} f \exp$ & $-0.002^{* * *}$ & 0.000 & -0.000 & 0.000 \\
\hline Prefil*hsorless & $-0.480^{* * *}$ & 0.023 & $-0.296^{* * *}$ & 0.040 \\
\hline Prefil ${ }^{*}$ someps & $-0.333^{* * *}$ & 0.030 & $-0.209^{* * *}$ & 0.043 \\
\hline Prefil*west & $0.168^{* * *}$ & 0.032 & $0.197^{* * *}$ & 0.047 \\
\hline Prefil $^{*}$ west $^{*}$ cexp & $-0.024^{* * *}$ & 0.006 & -0.020 & 0.013 \\
\hline Prefil $^{*}$ west $^{*}{ }^{*} \exp ^{2}$ & $0.001^{* * *}$ & 0.000 & 0.001 & 0.000 \\
\hline Prefil**west*fexp & $0.028^{*}$ & 0.014 & $0.033^{* * *}$ & 0.006 \\
\hline Prefil*west*fexp $^{2}$ & $-0.001^{*}$ & 0.000 & $-0.001^{* * *}$ & 0.000 \\
\hline Prefil ${ }^{*}$ west $^{*}{ }^{*}$ exp*fexp & -0.000 & 0.000 & $-0.001^{* * *}$ & 0.000 \\
\hline Prefil**west ${ }^{*}$ hsorless & -0.006 & 0.028 & $-0.179^{* * *}$ & 0.054 \\
\hline Prefil* $^{*}$ west $^{*}$ someps & 0.099 & 0.051 & -0.042 & 0.029 \\
\hline West* ${ }^{*} \exp$ & $-0.022^{* * *}$ & 0.003 & -0.002 & 0.009 \\
\hline West ${ }^{*} \operatorname{cexp}^{2}$ & $0.001^{* * *}$ & 0.000 & -0.000 & 0.000 \\
\hline West*fexp & $0.014^{*}$ & 0.006 & 0.002 & 0.009 \\
\hline West*fexp ${ }^{2}$ & -0.000 & 0.000 & 0.000 & 0.000 \\
\hline West ${ }^{*} \operatorname{cexp}^{*}$ fexp & $0.001^{* * *}$ & 0.000 & $0.000^{*}$ & 0.000 \\
\hline West*hsorless & -0.083 & 0.055 & $-0.100^{* * *}$ & 0.025 \\
\hline West ${ }^{*}$ someps & $-0.117^{* * *}$ & 0.021 & $-0.056^{* * *}$ & 0.014 \\
\hline Cexp & $0.101^{* * *}$ & 0.004 & $0.083^{* * *}$ & 0.005 \\
\hline Cexp ${ }^{2}$ & $-0.003^{* * *}$ & 0.000 & $-0.002^{* * *}$ & 0.000 \\
\hline Fexp & $-0.022^{* * *}$ & 0.002 & 0.002 & 0.003 \\
\hline$F \exp ^{2}$ & $0.000^{*}$ & 0.000 & $-0.000^{*}$ & 0.000 \\
\hline Cexp*fexp & $-0.001^{* * *}$ & 0.000 & $-0.001^{* * *}$ & 0.000 \\
\hline Cexp*9092 & $0.004^{* *}$ & 0.002 & $0.006^{* * *}$ & 0.001 \\
\hline Cexp*9396 & $0.004^{* * *}$ & 0.001 & $0.012^{* * *}$ & 0.004 \\
\hline Cexp*9799 & 0.001 & 0.001 & $0.008^{* * *}$ & 0.002 \\
\hline Cexp*0003 & $0.026^{* * *}$ & 0.001 & $0.035^{* * *}$ & 0.003 \\
\hline Cexp*0407 & $0.040^{* * *}$ & 0.004 & $0.053^{* * *}$ & 0.007 \\
\hline Cexp*0809 & $0.080^{* * *}$ & 0.013 & $0.096^{* * *}$ & 0.016 \\
\hline Fexp*9092 & $-0.003^{* * *}$ & 0.001 & $-0.002^{* * *}$ & 0.001 \\
\hline Fexp*9396 & $-0.011^{* * *}$ & 0.001 & $-0.011^{* * *}$ & 0.001 \\
\hline Fexp*9799 & $-0.012^{* * *}$ & 0.001 & $-0.014^{* * *}$ & 0.002 \\
\hline Fexp*0003 & $-0.009^{* * *}$ & 0.002 & $-0.006^{*}$ & 0.002 \\
\hline Fexp*0407 & $-0.008^{* *}$ & 0.003 & -0.002 & 0.003 \\
\hline Fexp*0809 & -0.003 & 0.004 & -0.003 & 0.003 \\
\hline Hsorless & $-0.148^{* * *}$ & 0.030 & $-0.231^{* * *}$ & 0.020 \\
\hline Someps & $-0.104^{* * *}$ & 0.023 & $-0.140^{* * *}$ & 0.016 \\
\hline$N$ & $4,225,855$ & & $1,693,520$ & \\
\hline$R^{2}$ & 0.156 & & 0.123 & \\
\hline
\end{tabular}

Notes: The dependant variable is the log of real earnings. The regression includes all the control variables in the conditional regression presented in Table 2 . Standard errors are clustered by province of residence ******* * Significant at $0.01,0.05$, and 0.10 levels, respectively 
countries, the former group has higher returns to foreign experience and lower returns for Canadian experience. ${ }^{36}$ For female immigrants, however, the returns to Canadian and foreign experience are similar for immigrants from the West and the Rest.

For male immigrants, the estimates of the interaction of West with prefil and experience indicate that, unlike their non-prefiler counterparts, prefilers from both regions receive positive returns to foreign experience. ${ }^{37}$ The interaction between West and prefil further indicates that the entry earnings of male prefilers from the West are higher than prefilers from the Rest. Specifically, while for a university- educated prefiler from the West with no foreign experience, entry earnings are $3 \%$ higher than a comparable non-prefiler, a university-educated prefiler from the Rest needs more than 3.2 years of foreign experience to have higher entry earnings than a comparable non-prefiler. However, the negative estimate for prefil $*$ west $*$ cexp suggests that the returns to Canadian experience are lower for prefilers from the West and hence indicate convergence in earnings of prefilers from the West and the Rest. For various levels of foreign experience, Figs. 4 and 5 plot the earnings advantage of male prefilers by region. The figures clearly illustrate that the return to foreign experience is higher for prefilers from the West than it is for prefilers from the Rest, suggesting, as one would expect, that human capital from Western countries is more portable to the Canadian labor market than from other countries.

As was the case for males, the estimates for female immigrants indicate that there are differences by regions between prefilers and non-prefilers. Female prefilers from the West perform better in the Canadian labor market than those from the Rest. In particular, the estimates suggest that while the returns to foreign experience for female prefilers from the Rest are not statistically significant, they are positive for female prefilers from the West. ${ }^{38}$ As illustrated in Figs. 6 and 7, similar to male prefilers, female prefilers from the West have significantly higher returns to foreign experience than their non-prefiler counterparts. However, their returns to Canadian experience decrease with foreign experience, resulting in earnings profiles that are flatter with increasing foreign experience.

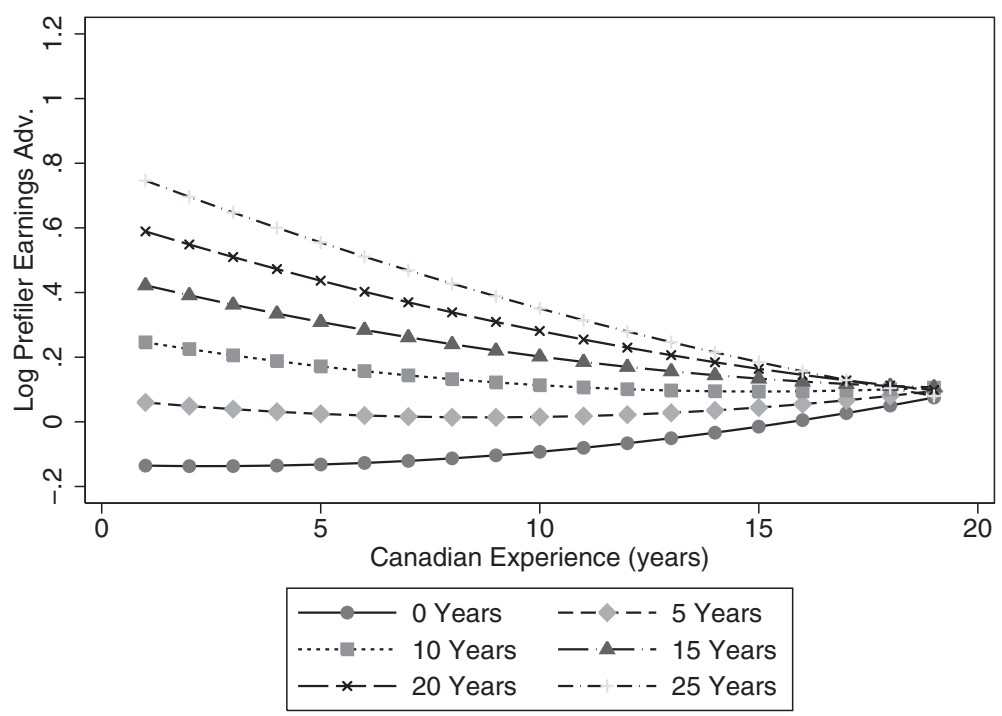

Fig. 4 Prefiler advantage (male): Rest 


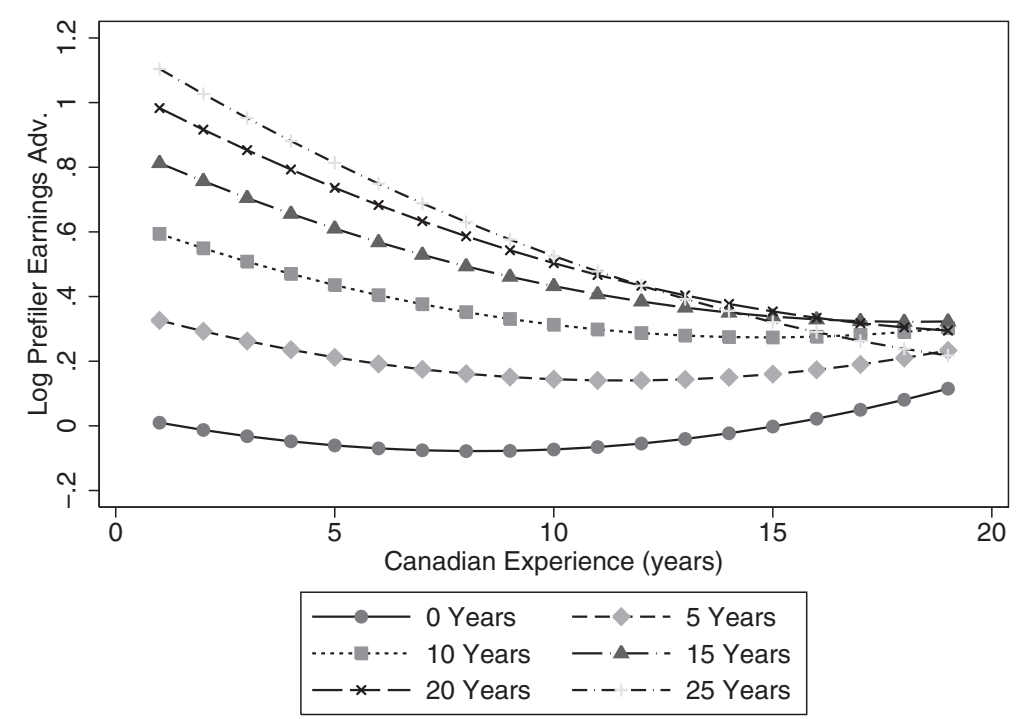

Fig. 5 Prefiler advantage (male): West

For both male and female immigrants, the coefficients on the interactions between prefil and the educational attainment variables replicate the findings from model 3 that compared to non-prefilers, differences in education across prefilers lead to greater differences in earnings outcomes, which is again consistent with greater returns to education for prefilers. The coefficients on the interactions between West, prefiler, and the educational categories indicate that this effect is similar for prefilers from the two broad regions.

Our findings indicate that the outcomes for prefilers differ by source region. In particular, prefilers from Western countries have better labor market outcomes than prefilers from other countries. These results are driven by high returns to foreign experience for prefilers from the West.

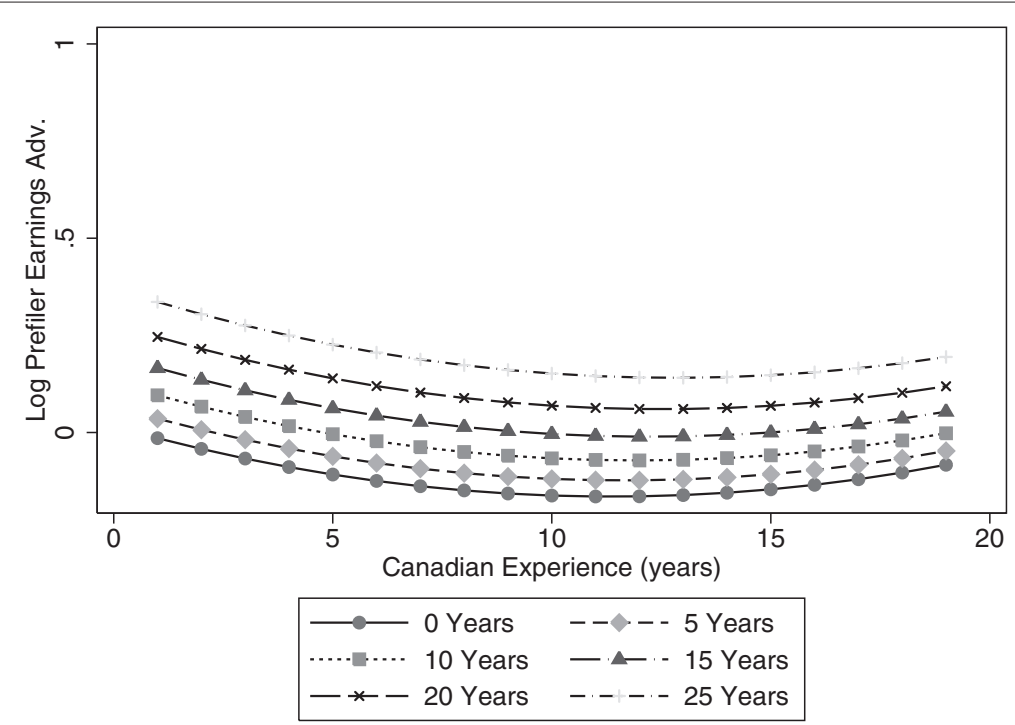

Fig. 6 Prefiler advantage (female): Rest 


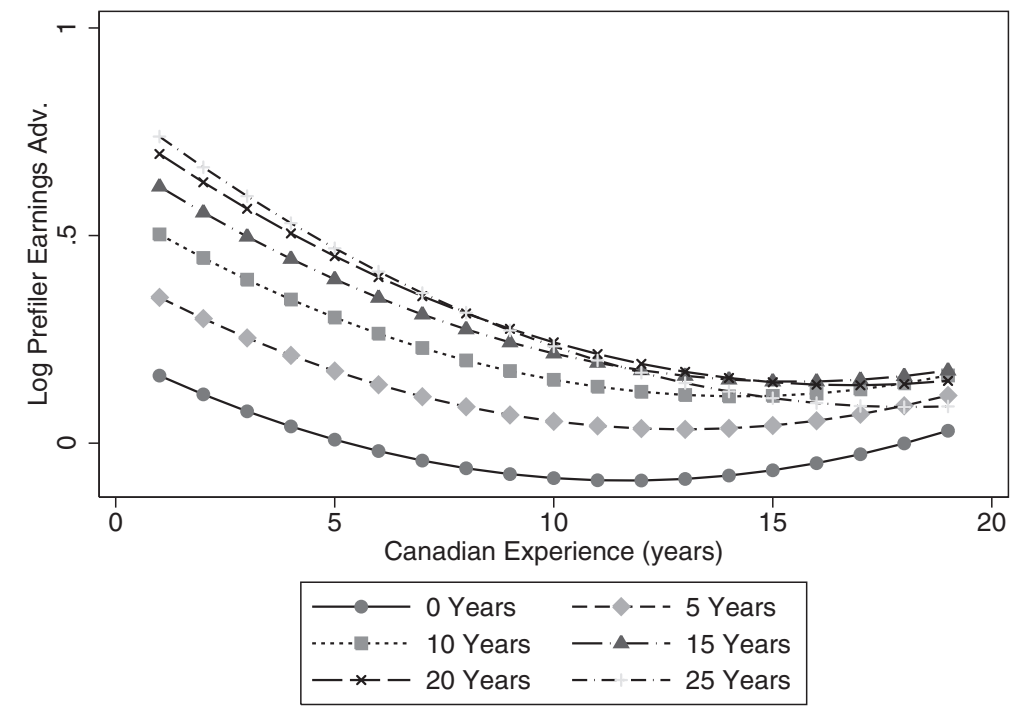

Fig. 7 Prefiler advantage (female): West

\section{Conclusions}

Our findings indicate that prior work experience in the host country is a predictor of labor market success of immigrants. We find that immigrants with prior experience have higher entry earnings and for male immigrants, this advantage persists for at least 20 years after arrival. We show that this advantage is related to the return to foreign experience. While male non-prefilers receive negative returns to foreign experience, male prefilers receive positive returns. Further, even though the returns to foreign experience are smaller for female than male immigrants, we find that female prefilers with a university education have a persistent earnings advantage over comparable non-prefilers. This suggests that policies, such as the CEC, which provide a path to permanent residency for temporary foreign workers that have acquired experience in the host country will improve immigrant labor market outcomes. In addition, we find that the prefiler earnings advantage is the largest for university graduates and that the return to foreign experience is higher for prefilers from Western countries than those from the rest of the world.

We qualify our findings with some caveats. First, our findings are based on a group of immigrants that were admitted through a migrant-driven system that did not prioritize employer preselection but did favor highly educated immigrants. Hence, the findings do not provide a comprehensive evaluation of the effects of recent changes in Canadian immigration policies. For example, the CEC, which is based on the skill level of the occupation for which Canadian experience has been obtained rather than the education of the immigrant, may result in a greater share of less-educated immigrants. As our results show, the economic outcomes of immigrants without a university degree are worse on average than those with a degree, and this difference is enhanced among prefilers. Studies in the future that evaluate programs like the CEC will examine these concerns and suggest ways in which to address them.

Second, it is unclear whether hybrid programs will eliminate the need for migrantdriven programs. In 2014, Canada admitted 78,107 principal applicants through economic programs (CIC 2015). Of these, 14,200 were admitted through the CEC, and 
another 28,733 were admitted through the Federal Skilled Worker program. While the CEC has grown dramatically since its inception in 2009 , there may be limits to the number of immigrants that can be recruited from foreign nationals working on a visa without also expanding the number of temporary visa workers in Canada. In other words, moving towards a more employer-driven system will require that the Canadian immigration policy consider the temporary worker visa programs as an integral part of the measures for selecting economic immigrants.

Third, preselection places greater weight on employer preferences, which may have implications for the diversity of selected immigrants. Our findings suggest that employers are more likely to choose immigrants that speak English as their mother tongue and/or are from Western countries. If employers discriminate on the basis of ethnicity or gender, placing greater weight on employer preferences will unintentionally institutionalize discrimination in the immigration selection process. To address this, additional scrutiny of the hiring of temporary foreign workers may be merited.

Overall, our findings suggest that a move towards a selection system for immigrants that uses previous host-country work experience as a criteria will improve the labor market performance of immigrants. The findings suggest that countries considering reforms to their immigrant selection policies should focus not only on retaining temporary foreign workers that have been preselected by employers but also on better integrating their temporary work visa programs with their immigration selection programs.

\section{Endnotes}

${ }^{1}$ These selection policies do not usually apply to family and refugee immigrants.

${ }^{2}$ The Canadian system contains some elements of an employer-driven system. Applicants are assessed on the basis of their characteristics using a points system and receive additional points if they have a job offer. However, prior to changes in the program that occurred after our study period, the points for a job offer were only a small share of the total required to qualify (Beine et al. 2016).

${ }^{3}$ Bertoli et al. (2016) discuss issues with selecting immigrants based on observable characteristics. Also, see (Belot and Hatton 2012) for a review of the selection of immigrants by level of education in OECD countries.

${ }^{4}$ Recent studies for Canada include (Abbott and Beach 2011; Aydemir 2011; Green and Worswick 2012; Picot and Piraino 2012; Sweetman and Warman 2014; Hou and Bonikowska 2015). Clarke and Skuterud (2013) compare the performance of immigrants to Australia and Canada to determine which country does better in selecting immigrants. Using longitudinal data, (Kaushal et al. 2015) compare the earnings and employment growth of immigrants in Canada and the USA. van de and Voitchovsky (2015) provide a review of the Australian skilled immigrant selection program. For a review of the literature, see (Kerr and Kerr 2011) and (Gaston and Nelson 2013).

${ }^{5}$ van de and Voitchovsky (2015) document the expansion of employer-driven immigration in Australia and find that it had a positive effect on short-term employment of skilled immigrants.

${ }^{6}$ Another recent change in the Canadian immigration selection policies has been the introduction of Provincial Nominee Programs. While these programs are largely employer-driven, some streams within the programs provide a pathway to permanent 
resident status for temporary workers without a job offer. For example, in Alberta, temporary workers that reside and have sufficient work experience in select occupations within the province are eligible for admission through the Strategic Recruitment Stream without a job or a job offer.

${ }^{7}$ For temporary workers, the CEC requires 12 months of full-time skilled work experience. There is still a language skills requirement, but unlike the Federal Skilled Worker program, there is no formal education requirement.

${ }^{8}$ The IMDB only has information on immigrants that filed taxes at least once between 1982 and 2012. For further details, see Section 2.

${ }^{9}$ The first year in which immigrants were admitted through the CEC was 2009. In 2014, $9.6 \%$ of principal applicants admitted through an economic program came through the CEC (CIC 2015).

${ }^{10}$ Economic categories include the Federal Skilled worker program, the Canadian Experience Class, and the various Provincial Nominee Programs.

${ }^{11}$ Similar to our findings, (Ostrovsky 2012) reports that approximately $20 \%$ of immigrants filed income taxes prior to immigration.

${ }^{12}$ Of prefilers obtaining landed immigrant status after 1991, 97 \% filed taxes 6 or fewer times prior to landing with $90 \%$ of these filing taxes continuously in Canada in the years immediately prior to immigration.

${ }^{13}$ Using earlier arrival years increases the likelihood that an immigrant had filed taxes in a year not covered in the IMDB.

${ }^{14}$ Aydemir and Skuterud (2005) use Canadian census data, and (Green and Worswick 2010) use data from the IMDB. However, both studies use data for immigrants to Canada through all programs: economic, family, and refugee.

${ }^{15}$ Western countries include Europe, the USA, and Oceania. Similar to our approach, Aydemir and Skuterud (2005) allow the returns to differ between Western and Eastern countries.

${ }^{16}$ Workers on temporary work visas are admitted on work visas through Canada's Temporary Foreign Worker program.

${ }^{17}$ See (Hanson and Slaughter 2013) and (Kahanec and Zimmermann 2011) for a discussion on high-skilled immigration programs in the USA and Europe, respectively.

${ }^{18}$ The comprehensive immigration reform bill, the Border Security, Economic Competitiveness and Immigration Modernization Act of 2013, was passed by the Senate in June 2013 but is pending approval from the House of Representatives.

${ }^{19}$ Given that (Hou and Bonikowska 2015) have data for the visa status of prefilers, they are able to evaluate differences in the earnings for prior work experience only, prior work and study experience, prior study experience, and prior other experience. They find that, compared to non-prefilers, prefilers with Canadian work permits had significantly higher earnings, with the largest advantage for prefilers with skilled employment. However, they find no evidence of an earnings advantage for prefiler international students without Canadian work experience. The data for visa programs for prefilers is only available within Statistics Canada; the dataset available to external researchers does not provide this information. We are thus unable to determine the differences between prefilers who are admitted in Canada through different visa programs.

${ }^{20}$ The data is available remotely from Statistics Canada. Researchers are required to submit their program codes to a Statistics Canada analyst who executes it, vets the output, 
and sends the results to the researcher. The vetting of output is done to ensure confidentiality of the data is preserved. Summary statistics and counts are rounded (for example, the number of observations used in the regression analysis is rounded to the nearest five), but regression coefficients and standard errors are reported "as is."

${ }^{21}$ We exclude economic class immigrants who immigrate through the home caregiver program from our analysis, as these immigrants are selected based on criteria that differs substantially from other economic classes (Hou and Bonikowska 2015). In addition, we include only immigrants that provided valid responses (excluding "unknown") to the various questions (demographics, source region, etc.) on the landing document.

${ }^{22}$ The IMDB does not include information on visas issued to immigrants prior to obtaining immigrant status.

${ }^{23}$ Employment earnings is the sum of employment and self employment income reported in the tax returns filed by individuals.

${ }^{24}$ In addition to issues with censoring, this exclusion was further necessitated by administrative errors in coding the educational attainment of immigrants landing in 2010 and 2011.

${ }^{25}$ The summary statistics used and reported in this section are derived from a set of custom tabulations compiling summary statistics for cells of immigrants based on sex, year of arrival, years since arrival, whether or not education full-time credits were claimed, and whether or not immigrants were from Western countries. Unless otherwise noted, summary statistics are computed as weighted averages using the cell counts.

${ }^{26}$ Foreign experience is imputed by subtracting 6 years plus an estimate of years in school from age at arrival. This adjustment factor varies by level of education as follows: 15 for secondary or less, 19 for individuals with a trade certificate or apprenticeship, 21 for individuals with some university but not a degree, and 23 for individuals with at least a university degree.

${ }^{27}$ To capture the Canadian business cycle patterns, we divide the time period 19882009 into seven arrival period cohorts: 1988-1989, 1990-1992 (recession), 1993-1996 (recovery), 1997-1999 (boom), 2000-2003 (dotcom bust), 2004-2007 (recovery), and 2008-2009 (financial crisis). As with (Aydemir and Skuterud 2005), we do not include interactions of $\mathrm{ysa}^{2}$ and the cohort dummies. This is done to avoid issues of collinearity with the most recent cohort, which is only observed for a few years after arrival.

${ }^{28}$ For example, a 35-year-old immigrant with a university degree is assumed to have been in school until 22 years of age, resulting in 13 years of subsequent work experience.

${ }^{29}$ Seasonally adjusted annual provincial unemployment rates for individuals aged 25 years and older were obtained from CANSIM Table 2820087.

${ }^{30}$ Previous studies (see, for example, Aydemir and Skuterud 2005; Green and Worswick 2012) define arrival of an immigrant as the year that permanent residence was obtained. In our study, arrival year for prefilers is the first year in which they filed taxes.

${ }^{31}$ The decomposition is undertaken using the estimated regression coefficients to obtain fitted means for the two groups of immigrants.

${ }^{32}$ Model 2 estimates for females imply that the earnings of observationally equivalent prefiler and non-prefiler females converge in about 4 years.

${ }^{33}$ We split total experience into Canadian and foreign experience by defining Canadian experience as the number of years in Canada since arrival and then computing the foreign experience as the difference between total experience and Canadian experience. In our 
regression, the quadratic in total experience is replaced by quadratics in each of Canadian and foreign experience and an interaction term between between the two.

34 This may be due to systematic differences in the types of prior experience of male and female prefilers. Hou and Bonikowska (2015) find that for males with prior experience, $34.6 \%$ were on skilled work visas, while another $18 \%$ were on a combination of student and skilled work visas. For females, the corresponding figures were 21.7 and $13 \%$, respectively. In their framework (see footnote 19), prior skilled work was associated with the largest earnings advantage.

${ }^{35}$ West takes a value of 1 for immigrants from Europe, the USA, and Oceania.

${ }^{36}$ Aydemir and Skuterud (2005) find lower returns to foreign experience for immigrants from Eastern countries. However, the countries classified as Eastern in their study are not the same as the countries classified as Rest.

37 The coefficient on the interaction between West, prefil, and fexp is positive and statistically significant at the .10 level.

${ }^{38}$ Among female prefilers, $68.4 \%$ from the West and $44.7 \%$ from the Rest had a university degree. Hence, the preimmigration experience of West prefilers would be in more skilled occupations than that of the Rest. Such differences in the type of preimmigration experiences of female immigrants from the West and the Rest may explain why prefilers from the latter group do not have the same earnings advantage as the former group.

\section{Acknowledgements}

We are grateful for the funding from the Social Science and Humanities Research Council (SSHRC) and technical support from Statistics Canada.

We would also like to thank an anonymous referee and the editor for the helpful suggestions.

Responsible editor: Denis Fougère.

\section{Competing interests}

The IZA Journal of Migration is committed to the IZA Guiding Principles of Research Integrity. The authors declare that they have observed these principles.

Received: 1 June 2016 Accepted: 3 August 2016

Published online: 14 February 2017

\section{References}

Abbott MG, Beach CM (2011) Do admission criteria and economic recessions affect immigrant earnings? Institute for Research on Public Policy, Study No. 22. http://irpp.org/research-studies/study-no22/

Aydemir A (2011) Immigrant selection and short-term labor market outcomes by visa category. J Popul Econ 24(2):451-75

Aydemir A, Skuterud M (2005) Explaining the deteriorating entry earnings of Canada's immigrant cohorts, 1966-2000. Can J Econ 38(2):641-72

Beine M, Boadway RW, Coulombe S (2016) Moving parts: immigration policy, internal migration and natural resource shocks. C.D. Howe Institute Commentary No. 446. https://www.cdhowe.org/public-policy-research/moving-partsimmigration-policy-internal-migration-and-natural-resource-shocks

Belot MV, Hatton TJ (2012) Immigrant selection in the OECD. Scand J Econ 114(4):1105-28

Bertoli S, Dequiedt V, Zenou Y (2016) Can selective immigration policies reduce migrants' quality?. J Dev Econ 119:100-9

Boyd M (2014) Recruiting high skill labour in North America: policies, outcomes and futures. Int Migr 52(3):40-54

CIC (2015) Facts and figures 2014 - Immigration overview: permanent residents. [Online (http://www.cic.gc.ca/english/ resources/statistics/facts2014/permanent/03.asp); accessed 15-March-2016]

Clarke A, Skuterud M (2013) Why do immigrant workers in Australia perform better than those in Canada? Is it the immigrants or their labour markets?. Can J Economics/Revue Canadienne D'économique 46(4):1431-62

Facchini G, Lodigiani E (2014) Attracting skilled immigrants: an overview of recent policy developments in advanced countries. Nat Inst Econ Rev 229(1):3-21

Gaston N, Nelson DR (2013) Bridging trade theory and labour econometrics: the effects of international migration. J Econ Surv 27(1):98-139

Green DA, Worswick C (2010) Entry earnings of immigrant men in Canada: the roles of labour market entry effects and returns to foreign experience. In: McDonald T., Ruddick E., Sweetman A., Worswick C. (eds). Canadian Immigration: Economic Evidence for a Dynamic Policy Environment. McGill-Queen's University Press Montreal and Kingston. pp $77-110$

Green, DA, Worswick C (2012) Immigrant earnings profiles in the presence of human capital investment: measuring cohort and macro effects. Labour Econ 19(2):241-59. http://www.journals.elsevier.com/labour-economics/

Hanson GH, Slaughter MJ (2013) Talent, immigration, and U.S. economic competitiveness. University of California San Diego. [Online (https://gps.ucsd.edu/_files/faculty/hanson/hanson_publication_immigration_talent.pdf); accessed 15-March-2016] 
Hou F, Bonikowska A (2015) The earnings advantage of landed immigrants who were previously temporary residents in Canada. Statistics Canada, Analytical Studies Branch Research Paper Number 370. http://www.statcan.gc.ca/pub/ $11 \mathrm{f0019m/11f0019m2015370-eng.htm}$

Kahanec M, Zimmermann KF (2011) High-skilled immigration policy in Europe. DIW Berlin Discussion Paper No. 1096. http://papers.ssrn.com/sol3/papers.cfm?abstract_id=1767902

Kaushal N, Lu Y, Denier N, Wang JS-H, Trejo SJ (2015) Immigrant employment and earnings growth in Canada and the U.S.: evidence from longitudinal data. National Bureau of Economic Research Working paper 21591. http://www.nber. org/papers/W21591

Kerr SP, Kerr WR (2011) Economic impacts of immigration: a survey. NBER working paper 16763. http://www.nber.org/ papers/w16736

Ostrovsky Y (2012) The dynamics of immigrant participation in entitlement programs: evidence from Canada, 1993-2007. Can J Economics/Revue Canadienne D'économique 45(1):107-36

Picot G, Piraino P (2012) Immigrant earnings growth: selection bias or real progress?. Statistics Canada Analytical Studies Branch Research Paper Series 340

Sweetman A, Warman C (2014) Former temporary foreign workers and international students as sources of permanent immigration. Can Public Policy 40(4):392-407

van de VenJ, Voitchovsky S (2015) Skilled migrants and labour market integration: how important is the selection process? IZA J Migr 4(1):1-28

Submit your manuscript to a SpringerOpen ${ }^{\circ}$ journal and benefit from:

- Convenient online submission

- Rigorous peer review

- Immediate publication on acceptance

- Open access: articles freely available online

- High visibility within the field

- Retaining the copyright to your article

Submit your next manuscript at $\boldsymbol{\wedge}$ springeropen.com 